\title{
Family-friendly governance in response to demographic challenges
}

Written by: Katalin Veresne Novák, Minister of State, Ministry of Human Capacities, Hungary

Last update: 2 December 2019

In Hungary, young people want to have bigger families, but concerns over issues like housing and striking a work-life balance appear to be obstacles. In response, the government has introduced a range of family-friendly policies-a vital step in helping families fulfil their dreams and in meeting the challenge of a rapidly ageing population.

Katalin Veresne Novák, Minister of State, Ministry of Human Capacities, Hungary

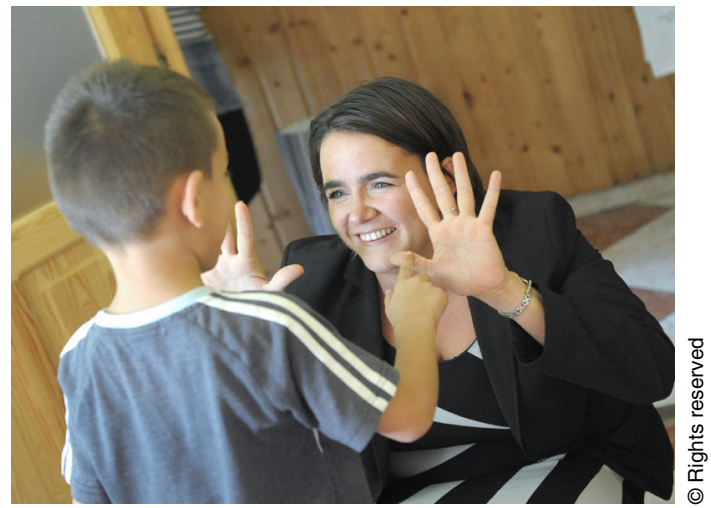

Hungary is a country with a current population of 10 million- an easy number to remember. Our grandchildren, however, may have to learn a different number. That's because of a demographic winter in Hungary, which, over the past 35 years, has resulted in a loss of 850,000 inhabitants. Even though the population is expected to increase worldwide in the coming 35 years, it will not in Hungary. The same is true of the vast majority of European countries, where low birth rates are the norm. Not only are developed countries facing low fertility rates but also, as a long-term result, the challenge of ageing populations. In Hungary, the number of elderly matched the number of children in 2006, and the ratio will deteriorate still further in the coming decades. Based on our projections, the consequences will be worse for Hungary than either the EU or the OECD average. Ageing has a negative impact on pension systems, health care, social care expenditures, labour markets and economic growth. 
Our double challenge since 2010 has been to find a long-term answer to the demographic decline and, at the same time, recover from economic, social and political crisis. Since 2010, domestic macroeconomic conditions have improved substantially as a result of the government's economic policy. Strict fiscal policy, consolidation of household balance sheets, structural reforms and a supportive monetary policy have all contributed to an above EU-average growth rate, decreasing debt levels and falling unemployment.

Population projections $2010-2050$

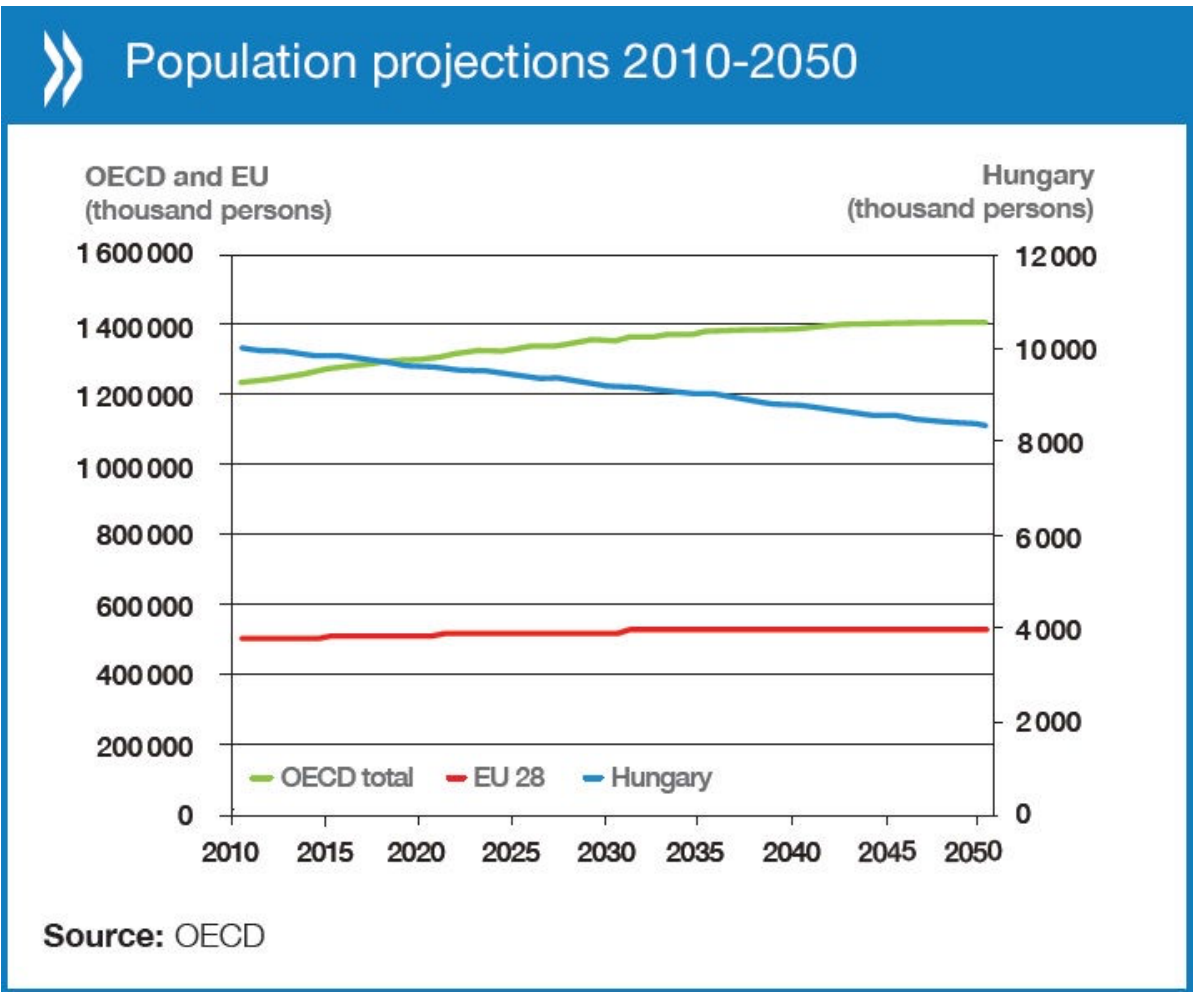

OECD

Quality is as important as quantity. The cornerstones of development are a strong and competitive education system, excellent health care and social care systems, and increasing labour market productivity and participation. In line with the OECD's inclusive development policy we have introduced a wide range of active and passive labour market measures-a widespread public work programme, tax reductions and benefits for employers and focused training, to name just a few. As a result, Hungary has its highest employment rate in 20 years, with stronger trends for participation and non-participation than either the EU or OECD averages.

Despite the negative trend, Hungary has a strong internal resource to meet our demographic challenge. While the average fertility rate is only 1.44 , young Hungarians say they actually want bigger families-on average they plan to have at least two children. The main reasons they cannot see these plans through are a 
lack of stable partnerships, housing problems, financial burdens and women's career plans. The government has introduced in the past five years a policy mix that supports families in a number of areas, including through taxation, better provision of housing, financial support and services, improving labour market conditions, and helping families to strike a better work-life balance.

Parents can benefit from three years of paid parental leave, while, thanks to new financial incentives, mothers are motivated to return to the labour market at an earlier stage. The family tax allowance system-which most families are eligible for-means working parents with an average income and at least three children do not have to pay any income tax. Day-care facilities are constantly being developed, offering free or inexpensive childcare, including four free meals a day for children.

The government has also recently introduced a housing programme, which offers a non-refundable cash benefit of up to about $€ 33,000$ for families. The largest sum is accessible for couples that are either prepared to raise or are already raising three children and decide to buy or build a new property.

The demographic crisis can only be solved over the long run . Despite this, we are already seeing some positive signs, which further strengthen our commitment to family-oriented policy

The demographic crisis can only be solved over the

\section{long run}

making. Fertility rates and women's employment are both at their highest levels in 20 years. We are still below the OECD average, but are convinced that the longterm, sustainable answer to demographic challenges can only be solved with pronatalist, family-friendly policies.

As Minister of State for Family and Youth Affairs, but also as a proud mother of three, I am especially passionate about creating a family-friendly environment in Hungary.

() OECD Yearbook 2016 